\title{
Safely re-opening a collapsed extraction level drive in a resource-limited environment
}

\author{
NA Shea Climax Molybdenum, USA \\ RW Sinclair Climax Molybdenum, USA \\ TM Welsh Climax Molybdenum, USA
}

\begin{abstract}
In May 2016, Henderson Mine was operating at a reduced rate when one of the extraction level drives experienced accelerating convergence in a $30 \mathrm{~m}$ section of drift. The converging area contained four drawpoints and an orepass opening. Attempts to address the convergence were unsuccessful and the area was abandoned by constructing bulkheads on each end of the converging zone.

In June of that year, accelerating convergence was again seen in the pair of drawpoints just south of the closure area. Given that the drift was closed to the north, the most practical method of securing the area was to stack the drawpoint intersection to the next pillar with muck and pump it full to the back with concrete. Following this, no further convergence of note occurred in the area.

Following closure of the area, the mechanism behind the convergence was investigated. A combination of factors including undercutting strategy, draw rates, and geology is believed to have contributed. Following understanding the mechanisms of the closure, time was allowed for the cave to mature while normal draw continued around the area. Only when the cave was believed to be fully developed around the area and the loading mechanism removed, was re-entry considered.

In April 2017, work began on re-opening the collapsed portion of the drive. In the past, these projects have been challenging efforts involving large quantities of chemical grout and heavy steel set work. With the operating environment and resources available, this methodology was no longer attractive. A simpler approach needed to be developed.

The methodology used was based on short advances with in-cycle support using the tools already on hand for normal repair and support operations. A combination of friction bolts, shotcrete, and inflatable bolts was used, supplemented with cable bolts and cement grout as needed. Work was done as resources could be made available and was stopped any time there was a question as to how to best approach the next advance.

This slow and steady approach allowed time for confirmation of the support effectiveness with each advance, as well as allowing other work to continue as required in the mine. The result has been successful re-mining of the drift, including re-opening of the orepass, with no safety incidents, no major stability issues, and with a minimum of impact to the rest of the operation.
\end{abstract}

Keywords: ground support, repair, stability, extraction level

\section{Introduction}

Henderson Mine is a continuous panel caving molybdenum mine located in the Rocky Mountains of Colorado. The mine has been in operation since 1976, producing at variable rates from three major extraction levels. The first of these was the 8100 level, which is now exhausted. The second was the 7700 level, which began production in 1992. The lowest and most recent level was the 7210 level, which began production in 2005. Current production is from the 7700 Southwest Panel, which is a new panel eight drifts wide, adjacent to the exhausted portion of the 7700 level, and to the west of the 7210 level below. 
The Henderson orebody is situated within a rhyolite porphyry intrusive complex. Each of the multiple intrusives are similar in composition and material properties. Historically, molybdenite grade (Rech et al. 2000) and alteration (McDonough 1976) have been found to have the greatest influence on the relative strength of the rock mass. High molybdenum grades have been associated with lower rock mass strengths as molybdenite veins and faults are low-friction discontinuities. Alteration has been found to affect the intact rock strength, with strengths ranging from $75 \mathrm{MPa}$ in areas subjected to weakening argillic alteration to $126 \mathrm{MPa}$ in areas with hardening potassic alteration (Campbell et al. 2010). The 7700 Southwest Panel extraction level is generally lower grade than previous production panels and has higher levels of potassic alteration and lower levels of argillic alteration, especially in the western portion of the panel. This has resulted in generally highly competent conditions on the extraction level in the panel.

The panel sits at a depth of approximately 1,400 m from the surface with draw columns of $120 \mathrm{~m}$ to the exhausted 8100 level. Extraction drifts are $24 \mathrm{~m}$ apart in the four drifts closest to the old 7700 production to match existing infrastructure, and $30 \mathrm{~m}$ apart in the rest of the panel. Drawpoint spacing is $17 \mathrm{~m}$ across the panel, which contains approximately 200 drawpoints.

The 7700 Southwest Panel was undercut, like all previous panels, using a traditional post-undercut method. Caving began in the southern portion of the panel adjacent to the old cave to the east. After initial undercutting, the cave was developed as a flat linear front perpendicular to the extraction drifts. For most of the panel, caving progressed at a rate of around three bells per month, until late 2015 when undercutting was accelerated to 12 bells per month. At this rate, the final third of the panel was undercut between November 2015 and January 2016.

As the cave grew, production from the $\mathbf{7 7 0 0}$ Southwest Panel gradually increased, transitioning away from the 7210 level. In January 2016, production rates at Henderson were reduced in response to market conditions. With this change, the workforce was also reduced to reflect production rates with no further caving or development activity. In mid-2016, the 7700 Southwest Panel was producing at about 9,000 tpd, accounting for roughly half of the mine's total daily production.

\section{Convergence event}

While operating at this reduced capacity, convergence that would result in closure occurred in May 2016, in the 615 drift of the 7700 Southwest Panel. Convergence began in the horizontal direction with bulking in the ribs followed by accelerating vertical closure.

At the time convergence was first noted, mucking was limited in the drift to allow for repair shotcrete operations. At Henderson, it is common to apply additional shotcrete in the extraction level drifts, especially after undercutting has been completed, to repair any damage to the surface support from abutment loading or production activities. While shotcrete work was ongoing, mucking activity was shifted to other areas. Given the competent nature of the rock on the extraction level, and previous experience showing little effect from short-term changes in draw, there was little concern that reduced draw during the repair cycle would have a noticeable effect. A similar repair cycle had been performed on several drifts on the panel since the reduction in production at the start of the year.

In the case of 615 , repair shotcrete work had begun at the southern end of the drift working to the north. The shotcrete crew had reached the northern of two orepass openings in the drift when, on 18 May 2016, they reported unusual noise and damage in the area. They reported behaviour similar to abutment loading conditions. Upon investigation, there was noticeable new damage in the area since convergence measurements were taken on 13 May, focused around faults to the north and south of the orepass opening. Given that undercutting was completed several months before, the first assumption was that the reduced draw for repair had resulted in minor differential loading in the caved material, and could be addressed with return to draw. The shotcrete crew was instructed to support the damaged areas as much as possible, and pull out so that draw could resume the following day. 
On 19 May, draw was resumed in the area, at a rate of approximately 300 tpd from each drawpoint. Mucking continued at this rate through 20 May. Convergence data is inconclusive on whether this resulted in a measurable reduction in convergence rates. On 21 May, mucking was stopped for a planned production shutdown. With production and support schedules limited, capacity was not in place to support any mucking activity on 21 to 22 May during this shutdown period.

Mucking resumed on 23 May for day and night shift. By day shift on 24 May, it was apparent that mucking was not sufficiently slowing the progression of damage. It was decided to halt mucking in the immediate area and move to plugging the affected drawpoints with concrete. This has been an effective measure in the past at Henderson in converging areas, dramatically reducing the effective extraction ratio in short order (Carlson et al. 2012). However, the area continued to progressively deteriorate. On 25 May 2016, as concrete formwork was being damaged before it could be pumped, work was stopped for safety.

Throughout the event, convergence had been limited to an area defined by faults to the north and south. When it was decided that no further remediation work could occur in the converging area, the solution was to build $50 \mathrm{~cm}$ concrete bulkheads just outside the area, where work could be completed safely. These bulkheads effectively isolated the closure area. Closure continued in the bulkheaded area, but minimal impact was seen in the surrounding drifts and activity returned to normal.

In under two weeks from first detection of damage to final abandonment, the $30 \mathrm{~m}$ converging area was safely identified and addressed. While several methods were used to attempt to mitigate the damage with the resources available, the decision to abandon the area ensured personnel were kept free from harm. With reduced production, operational goals were not impacted by the loss of one drift for an indefinite time.

\subsection{Second convergence event}

Following the initial convergence event, conditions in the surrounding area were stable for some time. Mucking proceeded normally to the east and west, while in 615 , supplementary ventilation was being put in place to allow for resumption of mucking outside the collapsed area. Windows had been placed in the bulkheads to allow for ventilation, but eventually were sealed off as the drift reached complete closure.

In late June 2016, convergence was seen again in 615. This was identified by visual observation and confirmed with handheld laser measurements. While the area to the north of the closure area remained stable, damage was seen in the south bulkhead and the drawpoint intersection to the south. With ventilation and access blocked to the north, options for addressing the closure were limited. Ventilation for the area was from an auxiliary fan from an adjacent drift, reducing loader productivity and making mucking at a high rate in both drifts impractical. Plugging drawpoints was also discussed, but given the experience in the previous closure, it was not clear that this work could be completed safely before the area would have to be abandoned.

An approach was needed that would secure the area safely, given the time, resource, and access limitations. While building another bulkhead was an option, allowing another $15 \mathrm{~m}$ of drift to fully collapse was less than ideal. After some discussion, a rapid backfill plan was developed. This would fill the void space of the drift to prevent excessive closure, and if all went well, be easier to remediate at a later date than a fully collapsed drift.

The drift and drawpoints in the converging intersection were stacked as full as possible with production muck from the adjacent drawpoints. Pipes were placed above the muck and the stacked face sealed with shotcrete. Approximately $70 \mathrm{~m}^{3}$ of concrete was then pumped into the space above the stacked muck. With this completed, mucking operations returned to normal. Monitoring continued through a combination of visual observations and convergence measurements.

Following the backfilling of the second closure area, no further convergence was seen in 615 to the north or south. Adjacent drifts were also closely monitored for damage, ultimately seeing little impact from the closure in 615 . In the drift immediately to the west of 615 , some damage was seen in the same fault structures that cross the 615 closure area, but with the application of supplementary support in the area, no significant closure was seen. 


\subsection{Convergence event analysis}

As soon as the bulkheads were in place in 615 isolating the initial closure area, work began on understanding the nature of the closure to assess the risk of further damage. While information on the exact nature of behaviour inside the cave is inherently limited, the following concept fits well with the available data and the experience of those involved.

As is often the case in complex systems, there is not a single root cause of the failure (Cook 2002). Rather, a combination of contributing factors influenced the final result. A number of these potential contributing factors were identified and evaluated.

The first factor considered was the reduced draw in the area for the repair cycle. The overall height of draw in the area was found to be around 1.5 to $3 \mathrm{~m}$ lower than the surrounding areas at the time of the event. However, it became clear that this could not be the sole factor in the closure given the isolated nature of the failure, and the history of similar operations with no effect on extraction level stability.

As the failure was notably defined by faulting on the north and south, geologic factors were considered next. In reviewing mapping data, these faults were found to be potentially continuous to adjacent extraction level drifts and the undercut. Molybdenum faults are ubiquitous at Henderson, and while they are a weak structure, they rarely present stability problems in isolation. Alteration was then also considered. On the extraction level, moderate argillic alteration was seen around the faulting which would result in some reduction in strength. This would be compounded by the high extraction ratio created by the orepass opening. On the undercut level, high potassic alteration was seen resulting in higher strength relative to the surrounding area (Figure 1).

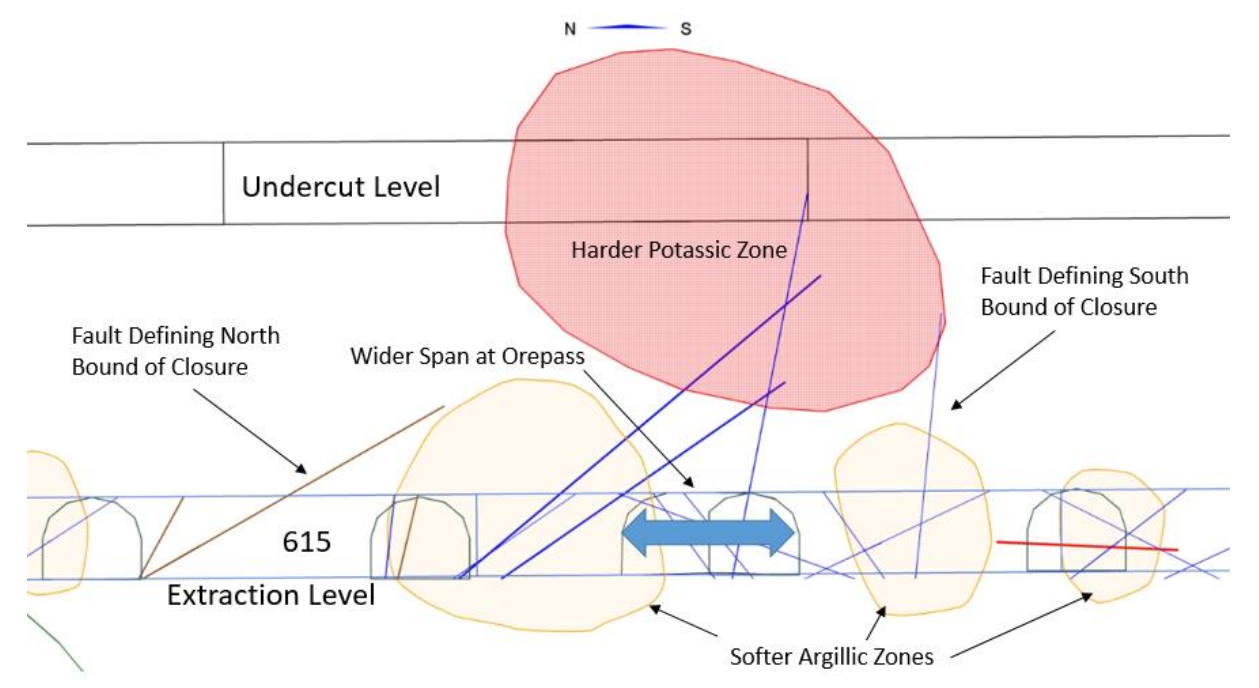

Figure 1 Geologic cross-section along 615 through the collapsed area. Initial failure was defined by the vein-fault between 705 and 707, and the fault between 709 and 711 . Secondary closure occurred in the 711 intersection. The potassic zone seen on the undercut level is higher strength material relative to the surrounding area

Lastly, undercutting was considered. Caving with a straight front across the length of the panel and perpendicular to the production drifts is common practice for Henderson. However, the rapid undercutting of the final third of the panel was a change. This may have created a large area of low cave back, which could cause point loading if geologic or draw factors allowed for stress transmission to the pillar apices. Potential stub pillars due to incomplete undercutting were discussed, but considered less likely to be a factor. Undercut drilling and blasting proceeded here in the same manner as in the rest of the panel with no issues noted. The competent nature of the ground at the undercut level reduces the likelihood of cut holes or similar issues in the blasting process. Without the ability to visualise the exact shape of the cave in the area at the time, the exact shape of the cave back remains an open question, but considering all factors involved and the failure mode of the drift, a broad low cave back was considered to be the most probable case. 
With these factors considered, a conceptual model of the failure was developed as follows: After rapid undercutting, a low cave back was present over the northern third of the production panel. Low draw rates across the panel meant that this low cave back was still present several months after undercutting. In 615 , above the orepass, a hard zone likely resulted in slower caving activity and a cave back even lower than the surrounding area. Assumed cave back geometry is shown in concept in Figure 2. When draw was stopped for repair in 615, this lower cave back was able to sit down, either on muck above the apex pillar, or directly on the pillar itself, transmitting load from the large undercut area. As shown in Figure 2, the more developed cave in the surrounding softer areas does not transmit stress, resulting in a concentration of load directly above the 615 orepass. This loading quickly overcame the strength of the pillar, which was less than normal in this location due to the high extraction ratio of the orepass opening. The pillar was then able to fail in isolation due to the faults to the north and south.

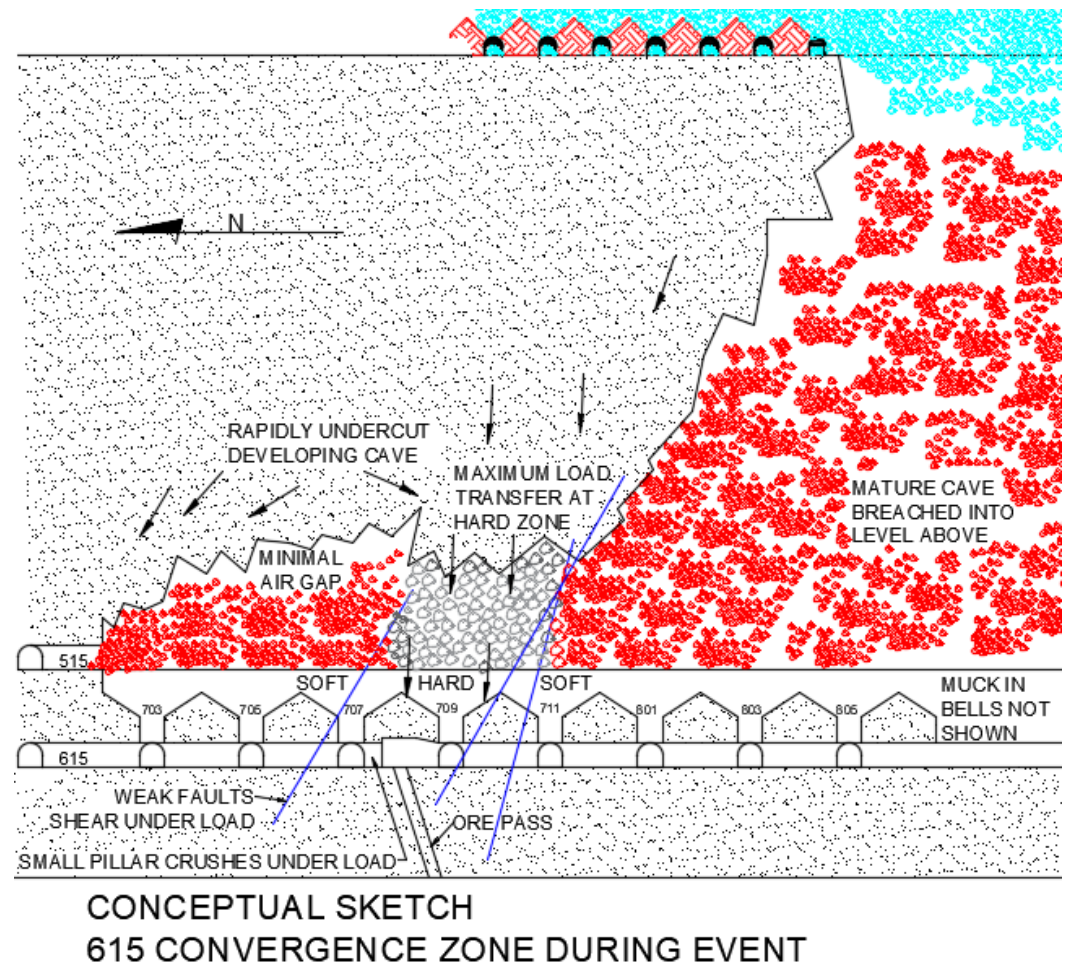

615 CONVERGENCE ZONE DURING EVENT

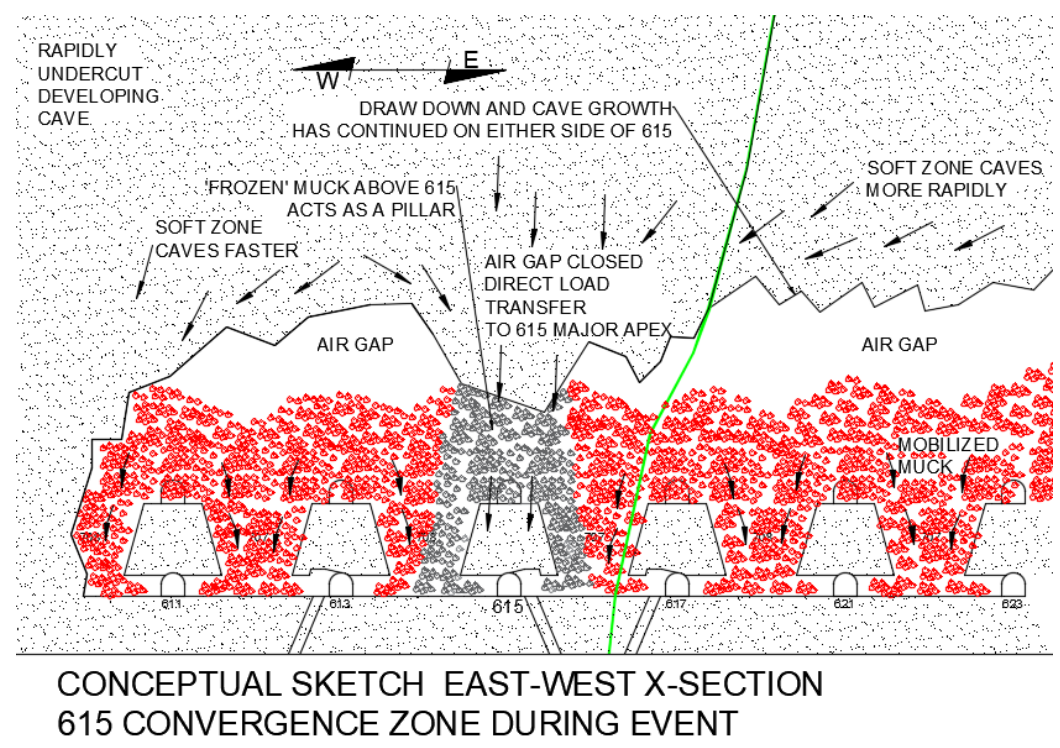

Figure 2 Conceptual sketches of the suspected failure mechanism developed following closure. Harder material above 615 allows load transmission from the cave back to the pillars around the orepass opening 
Once this loading had fully closed the initial area of collapse, the loading then continued to the south, resulting in the second closure event. When the secondary closure area was backfilled, enough pillar was in place to resist further loading while cave growth continued.

Working from this conceptual model, it was decided to allow the cave to mature further before any remediation of the collapsed area. Mucking priority was shifted away from the old 7210 production level to ensure consistent draw from the 7700 Southwest Panel and to facilitate growth of the presumed low cave back area. The surrounding area was closely monitored with a combination of laser distometer convergence measurements and visual observation. No further stability issues were encountered.

In the months following the event, operations returned to a steady state. The 615 closure was incorporated into numerical modelling back-analysis of caving behaviour in the panel. This would validate the conceptual model and aid in evaluating when, or if, the loading mechanism was likely to be removed from the area. This modelling, performed by Itasca (Fuenzalida et al. 2017), was helpful in both of these areas.

Using an innovative technique combining REBOP flow models (Itasca International, Inc. 2018a) and FLAC3D stress models (Itasca International, Inc. 2018b), the effects of undercutting and draw were able to be combined, showing the development of a low cave back area (Figure 3 ) and transmission of stress to the extraction level in the 615 drift (Figure 4).

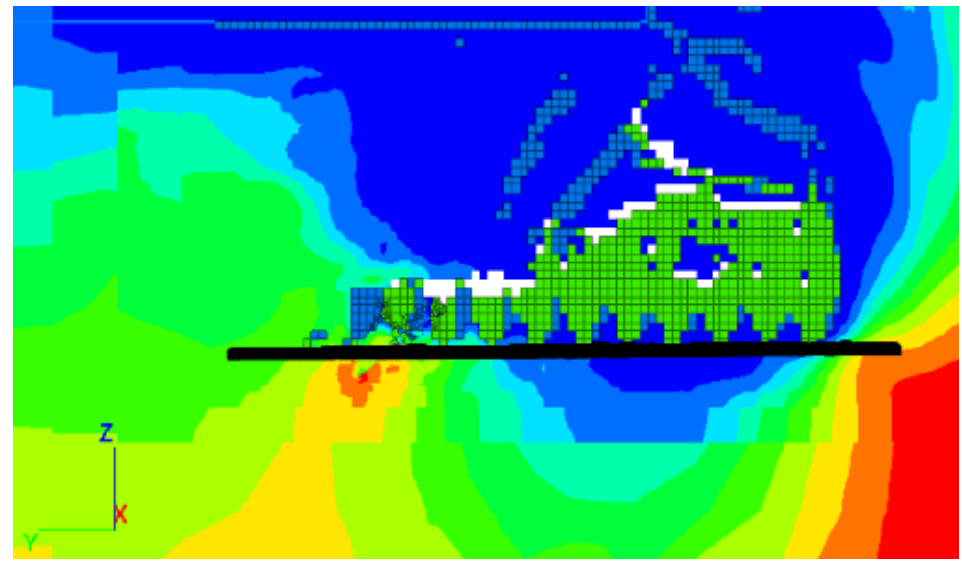

Figure 3 Numerical model results in a north-south section along 615 coloured by maximum principle stress. The mature cave area can be seen to the south, with mobilised muck shown in green. The low cave back can be seen to the north in the rapidly undercut area (Fuenzalida et al. 2017)

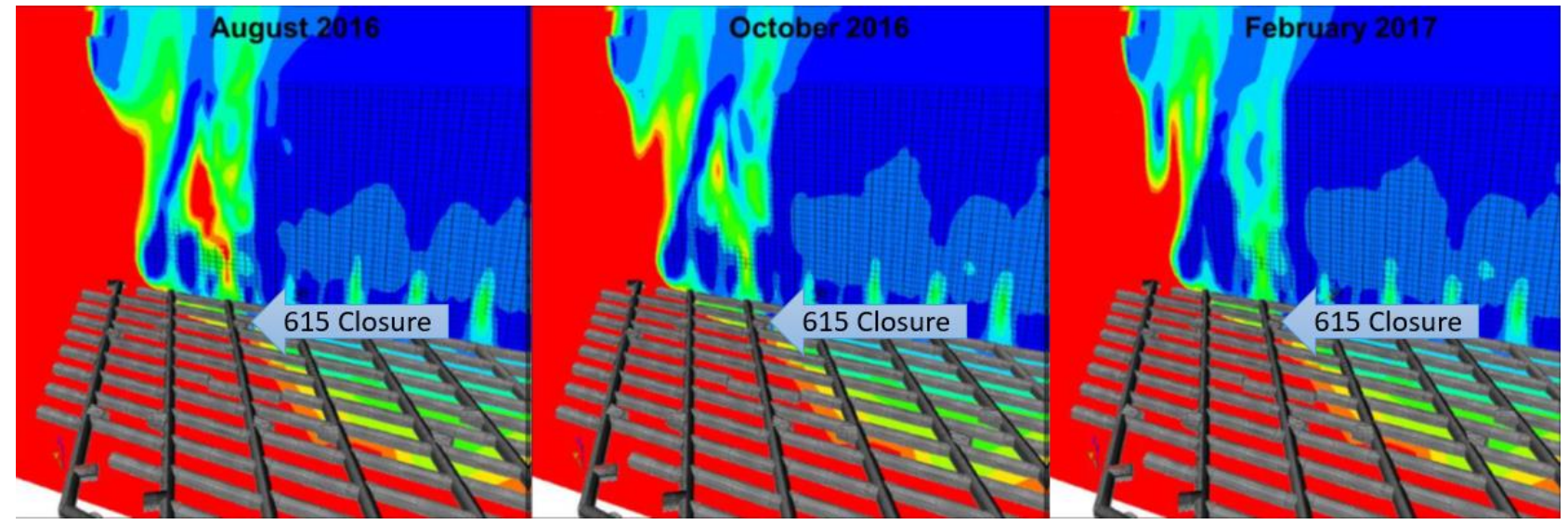

Figure 4 Oblique sections looking north of numerical modelling results coloured by vertical stress. Elevated vertical stresses can be seen transmitted through 615 , and reducing as the cave matures (Fuenzalida et al. 2017)

Perhaps equally importantly, this modelling showed a reduction in transmitted stress as the surrounding cave area grew to maturity. This would be critical, as re-mining through the area was being considered. 


\section{$3 \quad$ Re-mining}

By spring 2017, options to re-mine through the collapsed area were being reviewed. Production goals continued to be met, but producing from 615 under auxiliary ventilation was less than ideal. Not only was productivity in the 615 drift impacted, but because ventilation was supplied from the adjacent production drift, work could not safely be conducted in both drifts simultaneously. This limited flexibility in production scheduling and management of repair activities.

Re-establishing ventilation flow through the area would allow normal mucking operations in 615 and ensure that operational flexibility was in place to meet any future production needs. The challenge was in finding a way to achieve this while fitting with the current operational profile of Henderson Mine. The mine no longer had a dedicated mining crew as development operations had ceased in 2015. Repair activities were conducted by production personnel on an as needed basis only and scheduled with regular production duties.

Henderson's previous successful rehabilitation of a collapsed production drift in 2010 was accomplished using heavy steel work, spiling, and concrete backfill (Carlson et al. 2012).

With each advance, steel sets were stood, formed, and backfilled with concrete, prior to spiling and grouting ahead for the next round (Figure 5). While effective, this method involved large amounts of high-exposure, labour-intensive work, and significant cost. This approach was no longer attractive in Henderson's operating environment and the resources were not in place for it.
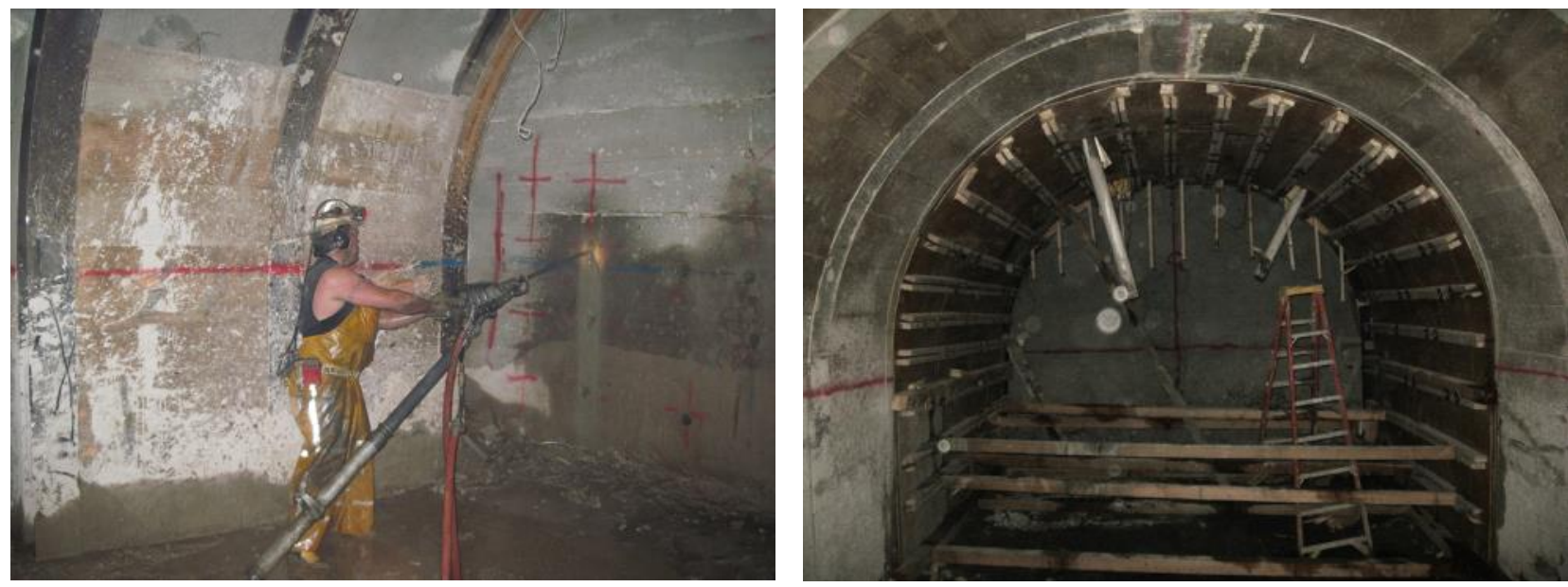

Figure 5 Re-mining through a collapsed extraction drift at Henderson in 2010. Cast concrete and steel arches were placed with each advance (from Carlson et al. 2012)

Contractor options were discussed, ranging from a similar traditional approach to pipe jacking an opening for ventilation only. All were found to be cost prohibitive and likely to have a high impact on the surrounding operation.

Since 2010, however, the Henderson team had gained experience tunnelling in weak ground using in-cycle shotcrete and inflatable bolts for support. As the team began to explore this more modern approach, it quickly resolved into a feasible option.

The plan developed was designed to be flexible enough to address the potentially variable conditions in the area. Initially, very short advances of just over $1 \mathrm{~m}$ would be taken with a load-haul-dump unit (LHD) or drilled and blasted as required. In most of the excavation, blasting would be required, with mining by free digging occurring only at the north and south ends. If running ground was encountered with this advance, work would be stopped and hollow bar spiling placed and cement grouted to stabilise the ground. Once the advance was taken, it would receive an initial support pass of $2.1 \mathrm{~m}$ friction bolts and mesh, followed by shotcrete. After placing this initial pass of shotcrete, $3 \mathrm{~m}$ long, $24 \mathrm{t}$ capacity inflatable bolts would be installed on $1.2 \mathrm{~m}$ spacing. If hole closure prevented inflatable bolt installation, grout tubes would be inserted into the 
holes and cementitious grout injected to improve the ground allowing for installation. If hole closure persisted, $3 \mathrm{~m}$ cement grouted hollow core bolts would be used in place of the inflatable bolts.

The multi-layered nature of this plan addressed a wide variety of potential ground conditions, and included built-in ground improvement in the most difficult conditions. It was feasible with the resources available, and was essentially a combination of familiar processes. It could be performed without altering production schedules or plans. In fact, the production schedule provided built-in opportunities to allow for grout curing or assessment. One final factor in providing the confidence to proceed was the success in stacking and backfilling the southern portion of the closure. The team knew that if loading conditions were different from expectations and closure started to reoccur, the drift could be rapidly backfilled, mitigating the damage.

\subsection{Advance through the collapsed zone}

The bulkhead on the northern end of the collapsed zone had been removed in March 2017 to assess conditions, and in April 2017, the first cautious advance was taken into the collapsed zone.

In this first advance, the fault structure that defined the northern extent of the failure was clearly seen, with the original back about half a metre from the floor of the drift sitting on broken rock. Perhaps the most striking feature in this first advance was the degree of compaction and interlock seen in the broken rock exposed (Figure 6). This was readily stabilised by the initial shotcrete and friction bolt support, and inflatable bolts were installed in all but the most broken portion (upper left in Figure 6). In this area, grout tubes were placed in the inflatable bolt holes and grout injected to locally improve the ground. Following grouting, the inflatables were installed successfully and advance could proceed.

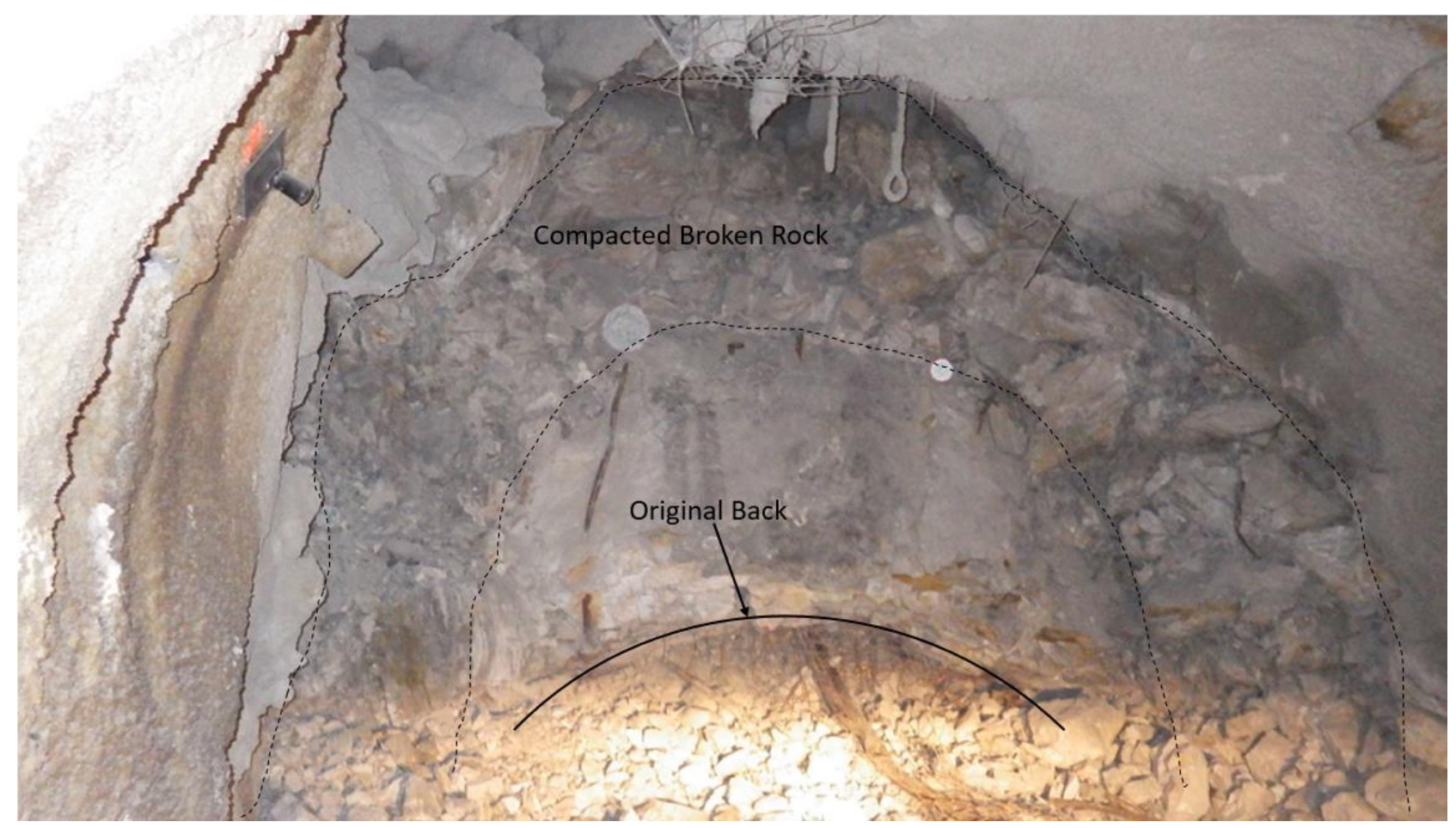

Figure 6 First exposure of the collapsed zone in 2017, prior to support installation. The original back can be seen sitting on broken rock just above the floor. Broken rock in the back and ribs of the new excavation is highly compacted

As advance continued into the collapsed area, conditions improved. Within a few metres, the ground could no longer be freely dug with an LHD and had to be blasted to advance. Pre-grouting was also no longer needed for inflatable bolt installation. Similar to what was seen in the area repaired in 2010, the back came down en masse, while the supporting rib pillars were crushed (Carlson et al. 2012). Work progressed when resources were available to work the area, making careful but steady progress. When the drawpoints were 
encountered, ground conditions became looser and pre-grouting was again required to install the inflatable bolts prior to advance. Once past the drawpoints, no further grout was needed and mining progressed routinely with in-cycle support until the orepass was encountered.

\subsection{Advance through the orepass opening}

When mining reached the orepass location, the original orepass cover was found intact and in position, with the original back now just above it. The orepass would be recoverable, but this would be approached with care to ensure the same safety and quality of excavation was maintained. To address the increased span of the finished excavation, $6 \mathrm{~m}$ cement grouted, single strand cable bolts were used instead of the inflatable bolts in the cycle. To ensure spans were manageable during the support process, cuts were limited to one half to one third of the total span. Each cut was fully supported, including grouting and tensioning of cable bolts, before the next advance. Time allowed for grout curing was not considered problematic as the crews were able to perform their regular duties elsewhere during those times.

Using this method, the orepass was opened and returned to service for the re-mining work. When the excavation was approaching its final span, cracking and damage began to be seen in the ribs on the far side of the orepass excavation. Cracking began on both ribs just inside the wider span of the orepass opening and continued back to the north for five to eight metres. This was the first evidence of any damage to the support system encountered in the mining process to date. Upon observation, this damage was not progressing continuously, but was increasing with each new advance.

Through the course of excavation, the ground in the ribs had been the most damaged. Additionally, support in the lower ribs was typically limited to friction bolts and surface support. It was determined that the lower ribs were not effectively carrying the load from the span in the orepass, and were deforming plastically each time the span increased. Before this resulted in greater stability problems, excavation was halted and a plan developed to reinforce the lower ribs.

A closely spaced pattern of $2.1 \mathrm{~m}$ friction bolts and $3 \mathrm{~m}$ hollow bar was installed in the lower ribs from the orepass opening back to the drawpoint intersection (Figure 7). Grout tubes were placed in the friction bolts and sealed, and the entire pattern was systematically grouted. Cementitious grout was placed through each bolt, proceeding row by row, from bottom to top. The grout through the friction bolts provided ground improvement near the surface with the hollow bar tying this into the deeper rock mass.

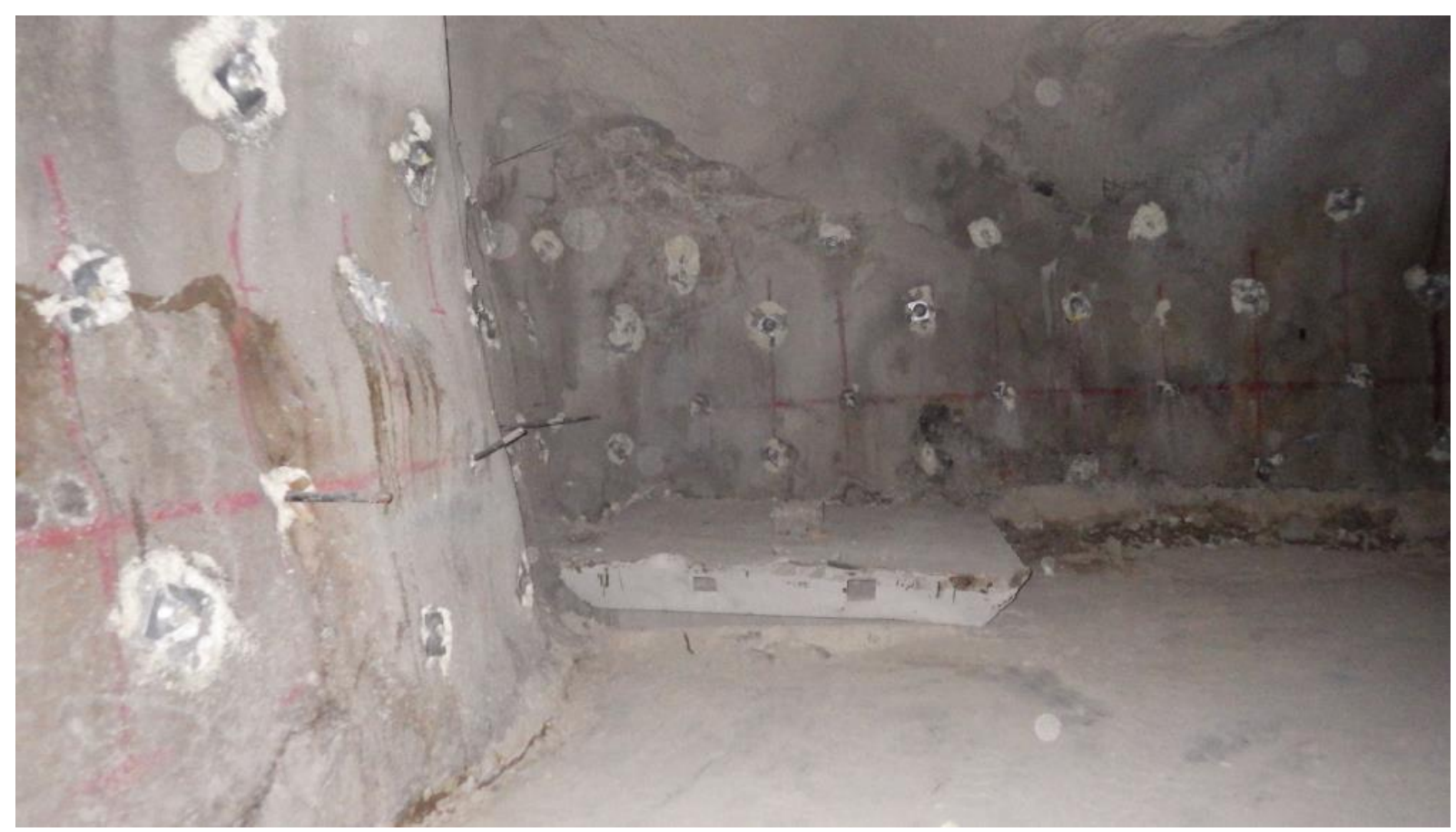

Figure 7 Friction bolts and hollow bar installed through the re-opened orepass for lower rib grouting 
After completion of this grouting campaign, advance resumed. The orepass span was completed without any further deformation or damage. Beyond the orepass, mining continued with inflatable bolts in-cycle for support until the end of the collapsed zone was reached.

At the southern end of the collapsed zone, a fault again clearly defined the extent of collapse. Past this fault, the original back and bulkhead were seen, about $1 \mathrm{~m}$ lower than the original height, but largely intact. All that remained was to pass through the backfilled zone.

\subsection{Advance through the backfilled zone}

Once the backfilled zone was reached, anticipation was high to see the performance of the stacked muck and pumped concrete placed 18 months previous. The results were better than anticipated. The drift profile was preserved and intact, although about $1 \mathrm{~m}$ lower than the original height. The backfill itself was impressively robust, especially considering the minimalist placement method. The bottom portion of the drift was able to be excavated with a loader, but the upper portion of the backfill formed a solid cemented rock bridge, tight to the back.

Advance through this area proceeded relatively rapidly by digging the bottom as far as could be reached safely, and then drilling and blasting the cemented portion away from the back (Figure 8). The original back was then secured with mesh and friction bolts and advance continued. The backfilled drawpoints were passed by, securing the surface of the backfill with friction bolts and mesh. Once breakthrough was completed, shotcrete was applied to complete repair of the surface support.

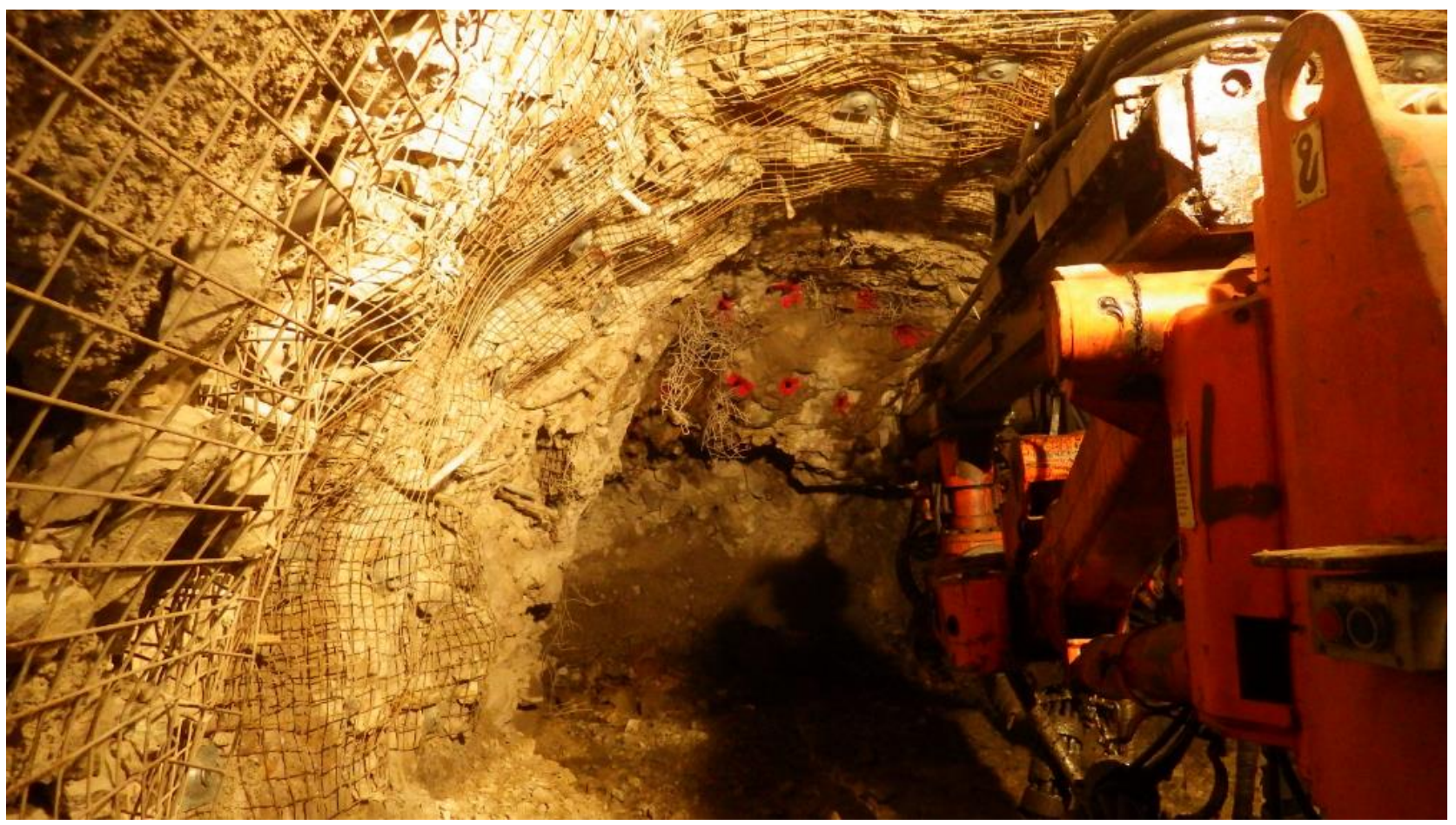

Figure 8 Excavation through the backfilled zone. A backfilled drawpoint is to the left. The lower portion of the backfill was excavated by LHD, prior to drilling and blasting the upper portion

\subsection{Results}

After 10 months, re-mining was safely completed and ventilation restored to the drift. $30 \mathrm{~m}$ of fully collapsed drift, including an orepass, along with $15 \mathrm{~m}$ of backfilled drift, was re-opened and supported. The area continues to be monitored and no further convergence or evidence of instability has been detected. As the project goal was to restore ventilation and production flexibility, the six drawpoints that were lost with closure were not re-opened. Re-opening those drawpoints may be considered at a later date if economics warrant. The drift re-opening was completed with limited resources, as they became available. Other 
operations around the mine were not disrupted and production needs were met throughout the project. The materials and tools used were available onsite, minimising cost impacts. By using a combination of familiar techniques in new ways, the work was well understood and executed in the field, resulting in a high quality finished product.

\section{Conclusion}

Even in a constrained environment, the Henderson team was able to safely respond to and address difficult conditions. Building on the knowledge and experience of the team, they were able to understand the situation and plan accordingly. They were able to develop and execute a remediation plan that was suited to the current operational profile and prepared the operation to meet future needs. The methods developed through this process and their success in implementation will also provide the team with new options in future situations.

\section{Acknowledgement}

The authors would like to recognise all of the operational personnel who worked in this area. The safety consciousness, awareness, and communication from operators at the face were instrumental in the success of this effort.

\section{References}

Campbell, R, Barnett, W \& Jakubec, J 2010, Geotechnical Characterization of the Dailey Zone Henderson Mine, unpublished report, SRK Consultants, Vancouver.

Carlson, GK, Sinclair, RW \& Long, DR 2012, 'Henderson's successful rehabilitation of a collapse production drift: a case history', Proceedings of MassMin 2012, Canadian Institute of Mining, Metallurgy and Petroleum, Westmount.

Cook, RI 2002, How Complex Systems Fail, Cognitive Technologies Laboratory, Chicago, viewed 19 July 2018 , https://www.researchgate.net/publication/228797158_How_complex_systems_fail

Fuenzalida, M, Katsaga, T \& Pierce, M 2017, Analysis of Cave Propagation and Drift Closure in 7700SW Panel, unpublished report, Itasca International, Inc., Minneapolis.

Itasca International, Inc. 2018a, REBOP, computer software, Itasca International, Inc., Minneapolis, https://www.itascainternational.com /products/software/consulting-software\#rebop

Itasca International, Inc. 2018b, FLAC3D, computer software, Itasca International, Inc., Minneapolis, https://www.itascacg.com/ software/flac3d

McDonough, JT 1976, 'Site evaluation for cavability and underground support design at the Climax mine', Proceedings of the 17th U.S. Symposium on Rock Mechanics, American Rock Mechanics Associated, Alexandria.

Rech, WD, Keskimaki, KW \& Stewart, DR 2000, 'An update on cave development and draw control at the Henderson Mine', Proceedings of MassMin 2000, The Australasian Institute of Mining and Metallurgy, Melbourne, pp. 495-505. 
